\title{
Extraction of Artemisinin, an Active Antimalarial Phytopharmaceutical from Dried Leaves of Artemisia annua L., Using Microwaves and a Validated HPTLC-Visible Method for Its Quantitative Determination
}

\author{
Himanshu Misra, ${ }^{1,2}$ Darshana Mehta, ${ }^{1}$ Bhupendra Kumar Mehta, ${ }^{1}$ \\ and Dharam Chand Jain ${ }^{2}$ \\ ${ }^{1}$ Natural Products Research Laboratory, School of Studies in Chemistry and Biochemistry, Vikram University, \\ Ujjain, Madhya Pradesh 456 010, India \\ ${ }^{2}$ Green Technology Department, Ipca Laboratories Limited, Ratlam, Madhya Pradesh 457 002, India \\ Correspondence should be addressed to Himanshu Misra; himanshumisra1@rediffmail.com \\ and Dharam Chand Jain; dc_52@rediffmail.com
}

Received 23 May 2014; Accepted 7 September 2014; Published 1 October 2014

Academic Editor: Qizhen Du

Copyright (C) 2014 Himanshu Misra et al. This is an open access article distributed under the Creative Commons Attribution License, which permits unrestricted use, distribution, and reproduction in any medium, provided the original work is properly cited.

\begin{abstract}
A simple, rapid, precise, and accurate high-performance thin-layer chromatographic method coupled with visible densitometric detection of artemisinin is developed and validated. Samples of the dried Artemisia annua leaves were extracted via microwaves using different solvents. This method shows the advantage of shorter extraction time of artemisinin from leaves under the influence of electromagnetic radiations. Results obtained from microwave-assisted extraction (MAE) were compared with hot soxhlet extraction. Chromatographic separation of artemisinin from plant extract was performed over silica gel $60 \mathrm{~F}_{254}$ HPTLC plate using $n$-hexane : ethyl acetate as mobile phase in the ratio of $75: 25, \mathrm{v} / \mathrm{v}$. The plate was developed at room temperature $25 \pm 2.0^{\circ} \mathrm{C}$. Artemisinin separation over thin-layer plate was visualized after postchromatographic derivatization with anisaldehyde-sulphuric acid reagent. HPTLC plate was scanned in a CAMAG's TLC scanner 3 at $540 \mathrm{~nm}$. Artemisinin responses were found to be linear over a range of 400-2800 ng spot ${ }^{-1}$ with a correlation coefficient 0.99754 . Limits of detection and quantification were 40 and $80 \mathrm{ng}$ spot $^{-1}$, respectively. The HPTLC method was validated in terms of system suitability, precision, accuracy, sensitivity (LOD and LOQ), and robustness. Additionally, calculation of plate efficiency and flow constant were included as components of validation. Extracts prepared from different parts of the plant (leaves, branches, main stem, and roots) were analyzed for artemisinin content, in which, artemisinin content was found higher in the leaf extract with respect to branches and main stem extracts; however, no artemisinin was detected in root extract. The developed HPTLC-visible method of artemisinin determination will be very useful for pharmaceutical industries, which are involved in monitoring of artemisinin content during different growth stages (in vitro and in vivo) of A. апnиa for qualitative and quantitative assessment of final produce prior to commercial-scale processing for assessment of cost-benefit ratio.
\end{abstract}

\section{Introduction}

Malaria is a vector-borne infectious disease, which affects approximately 400 million people every year, especially in Africa. The parasite responsible for fatal malarial infections is Plasmodium falciparum. The first effective antimalarial drug to treat this dangerous infection was quinine; since then, malaria has been treated with quinoline-based drugs like chloroquine, mefloquine, and pyrimethamine, but malaria parasite developed resistance to these drugs [1-3]. Artemisinin (Figure 1) is a natural product obtained from an aromatic annual herb of Asian and East European origin Artemisia annua L., which belongs to the family Asteraceae (Compositae). Due to the problem of resistance, artemisinin and its semisynthetic derivatives artemether, arteether, and artesunate are considered to be the most effective for the 


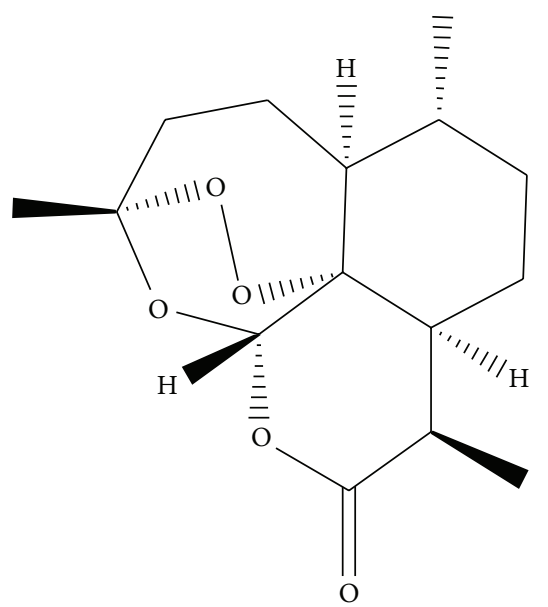

FIGURE 1: Structure of artemisinin.

treatment of uncomplicated malaria due to Plasmodium falciparum (through ACTs) and complicated cerebral malaria (through monotherapy). Central Institute of Medicinal and Aromatic Plants (CSIR-CIMAP), Lucknow, introduced Artemisia annua in India and developed its agrotechnology for commercialized production of active antimalarial drug, artemisinin [4-8]. Artemisinin has received much attention in the treatment of drug-resistant malaria in recent years, and it is now considered a potential candidate to reduce coccidial infection in chickens $[9,10]$. Besides antimalarial activity, artemisinin and its derivatives also possess several bioactivities [11] including antiviral [12], antitumor [13], and anticancer [14].

Presently, most common commercial sources of artemisinin are field-grown leaves and flowering tops of $A$. апnиa that are subject to seasonal and somatic variation. Today, the search for increased productivity follows two trends: the search for new species with better yield and a further development and application of methods for genetic improvement [15]. Mannan et al. in 2008 [16] described that chemical synthesis of artemisinin is known to be tedious and expensive. Therefore, search for other Artemisia species containing artemisinin and the plant source such as callus [17], shoot $[18]$, and hairy root cultures $[19,20]$ are also attractive alternatives. Although presence of artemisinin is supposed to be in Artemisia genus, there are reports describing presence or production of artemisinin in species other than A. annua [10, 16, 21-27]. Presence of artemisinin has been reported in $A$. cina (reported from Indonesia) [21], A. sieberi (reported from Iran) [10], A. absinthium (reported from Pakistan) [22], $A$. dubia and A. indica (reported from Pakistan) [16], and A. apiacea and A. lancea [23, 24]. Mannan et al. (2010) collected 17 different Artemisia species from different hilly locations in northern Pakistan and screened for the presence of artemisinin; results of this study revealed that artemisinin was present in 16 species (A. moorcroftiana, A. vestita, A. vulgaris, A. indica, A. sieversiana, A. roxburghiana var. roxburghiana, A. roxburghiana var. gratae, A. parviflora, A. dracunculus var. dracunculus, A. dracunculus var. persica, A. aff. Tangutica, A. annua, A. absinthium, A. bushriences, A. japonica, and
A. dubia) and in one species (A. desertorum) artemisinin was not present [25]. Suresh et al. (2011) detected artemisinin in A. abrotanum and A. pallens by LC/MS method [26]. On the other hand, Namdeo et al. in 2006 [27] stated that the genus Artemisia includes ca. 400 species; many of these species have been screened for the presence of artemisinin but only $A$. annua and to a lower extent $A$. apiacea were found to produce artemisinin. A. annua and A. apiacea were known to the Chinese in antiquity and since they were easily confused with each other. Recently, El-Naggar et al. (2013) reported extremely high artemisinin concentration $(4.85-4.90 \% \mathrm{w} / \mathrm{w})$ in their study performed in the Egyptian desert for the first time as a new promising cultivating area for pharmaceutical production of artemisinin [28].

A number of analytical methods have been developed for detection and quantification of artemisinin, like thin-layer chromatography (TLC) $[29,30]$, TLC with visible light densitometric detection (TLC) [31-34], high-performance liquid chromatography with UV detection (HPLC-UV) [35-38], HPLC with electrochemical detection (HPLC-ECD) [39, 40], HPLC with evaporative light scattering detection (HPLCELSD) [31-44], HPLC with peroxyoxalate chemiluminescence detection (HPLC-PO-CL) [45], HPLC/tandem mass spectrometric (LC/MS/MS) method [46], liquid chromatography/mass spectrometry (LC/MS) [47], high-performance capillary electrophoresis using self-designed conductivity detection system [48], gas chromatography with mass spectrometric detection (GC-MS) [49], GC with flame ionization detection (GC-FID) [50], and enzyme-linked immunosorbent assay (ELISA) [51]. Recently, spectrophotometric determination of artemisinin and dihydroartemisinin was reported from India [52].

The TLC method developed by Gupta et al. in 1996 [31] is really good, but validation parameters were not discussed in detail. Later on, Bhandari et al. in 2005 [34] developed RPTLC method for simultaneous determination of artemisinin, artemisinic acid, and arteannuin-B. This method is very good and well validated but costlier due to higher cost of RP-TLC plates. Additionally, as per the densitogram figure, the baseline separation between artemisinic acid and artemisinin was not achieved. So, it cannot be utilized for the routine analysis of artemisinin in industrial scale batch processing. Additionally, both of the methods $[31,34]$ are suffering from longer sample preparation time.

During the active plant ingredient determination, preparation of samples is the most time-consuming step(s) for the sample under test. In some cases, traditional solid-liquid (soxhlet) extraction of the herb sample performed, which is very time-consuming step and varies from a few hours to sometimes many hours. Several methods have been reported for the measurement of artemisinin in herbal samples [3134]; however, most of them are either not sufficiently sensitive and do not offer reliable results or are difficult to apply in routine analysis. Therefore, advanced methods for extraction and determination of these compounds, such as supercritical fluid extraction and chromatography, pressurized solvent extraction, microwave-assisted extraction, high-performance liquid chromatography coupled to mass spectrometry or evaporative light scattering detection, and its 
applications to plant material, pharmaceutical formulations, and biological fluids have been reviewed by Christen and Veuthey, (2001) [53]. Recently, Hao et al. (2002) [54] presented microwave-assisted extraction study of artemisinin from $A$. annua leaves, but in this study microwave irradiation time was 12 minutes, which is more. Additionally, number 6 extraction solvent oil showed good results, but it is not commonly available solvent for extraction. Although study by Hao et al. is good, applications of many commonly available solvents were not performed for artemisinin extraction under microwave irradiation.

Herein, we have developed a safe, effective, low cost, and fast microwave-assisted extraction (MAE) procedure for artemisinin from dried leaves of Artemisia annua together with an HPTLC method for its rapid and precise analysis under visible light detection at $540 \mathrm{~nm}$. Data obtained from microwave-assisted extraction has been compared with the data obtained from hot soxhlet extraction. This study reports a faster sample preparation method with a validated procedure for determination of artemisinin by HPTLC method. Flow constant and number of theoretical plates (plate efficiency) were evaluated and included as parts of validation.

\section{Material and Methods}

2.1. Plant Material. Plant material was grown in our experimental field at Ipca Laboratories Limited, Ratlam (M.P., India), after transfer of agrotechnology of high yielding $A$. annua variety "Jeevanraksha" $[55,56]$ from CIMAP, Lucknow, India. The leaves of the plant were taken, air-dried, and pulverized via mechanical grinder to a fine powder.

2.2. Chemicals and Reagents. All solvents used in this study were of analytical grade. Precoated silica gel $60 \mathrm{~F}_{254}$ HPTLC plates were purchased from E. Merck (Darmstadt, Germany). Artemisinin (control code: 103222) was purchased from WHO Centre for Chemical Reference Substances, Stockholm, Sweden (HPLC purity of artemisinin = 99.6\%). Anisaldehyde-sulphuric acid reagent was prepared by mixing $5 \mathrm{~mL}$ of anisaldehyde in $500 \mathrm{~mL}$ of glacial acetic acid in a beaker and stirred continuously over a magnetic stirrer; after 5 minutes, $10 \mathrm{~mL}$ of concentrated sulphuric acid (98\%) was added slowly to the above solution, through side-wall of beaker, and was stirred continuously for 10 minutes, after complete addition of acid. Now, this reagent is ready for postchromatographic derivatization of developed TLC plates.

2.3. Apparatus. A microwave apparatus with operating power 160-800 watts was used for MAE. Minimal possible operation time and power were 10 seconds at $160 \mathrm{~W}(20 \%$ power). A computerized TLC scanner 3 with winCATS online Planar Chromatography Manager version 1.3.4 (CAMAG, Switzerland) was used for quantitative chromatographic evaluation of test spots. CAMAG's Linomat 5 was utilized for nitrogen gas-assisted and controlled application of sample spots onto HPTLC plate. Drying and concentration steps were performed using rotatory evaporator (Büchi, Switzerland) model number R-205 equipped with an auto-vacuum

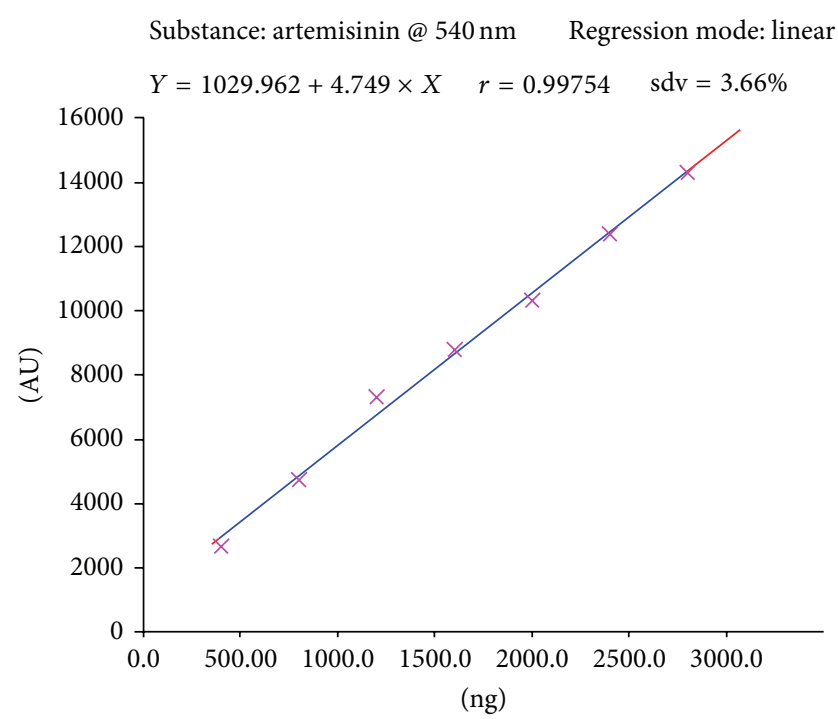

FIGURE 2: Calibration curve of artemisinin.

controller (model number V-800). Ultrasonicator (Enertech, Mumbai, India) was used for homogenizing of test and standard solutions.

2.4. Preparation of Artemisinin Reference Standard Solution and Calibration Curve. $10 \mathrm{mg}$ of artemisinin reference standard was dissolved in $10 \mathrm{~mL}$ of methanol. A portion $(5 \mathrm{~mL})$ of this solution was taken in a $25 \mathrm{~mL}$ volumetric flask and diluted up to mark with methanol to get a standard solution of $0.20 \mathrm{mg} \mathrm{mL}^{-1}$ concentration for quantification purpose. A calibration curve was plotted between increasing amounts of artemisinin per spot and their peak area response. A straight line was obtained between 400 and $2800 \mathrm{ng} \mathrm{spot}^{-1}$ (Figure 2).

2.5. Stability of Artemisinin Reference Standard Solution at Room Temperature. To study the stability behavior of artemisinin, in working standard solution, it was kept at room temperature (room temperature ranges from 21 to $30^{\circ} \mathrm{C}$ ) for two months and this solution was analyzed after 1 month and 2 months. It was observed that, due to degradation, artemisinin was reduced by $3.93 \%$ and $4.54 \%$ after one month and two months, respectively. During rainy season, artemisinin deteriorates even up to $9.0 \%$ after 2 months of storage at room temperature (Figure 3).

2.6. Soxhlet Extraction and Test Sample Preparation. $100 \mathrm{mg}$ of fine powder was placed into an extraction thimble and extracted with $170 \mathrm{~mL}$ of solvent ( $n$-hexane, benzene, toluene, chloroform, methylene dichloride, ethyl acetate, acetone, methanol, and acetonitrile) via hot soxhlet extraction method for 6 hours over a water bath. The extract was evaporated in vacuo and redissolved in $5 \mathrm{~mL}$ methanol. $10 \mu \mathrm{L}$ of these test solutions was used for quantification purpose.

2.7. Microwave-Assisted Extraction and Test Sample Preparation. $100 \mathrm{mg}$ of fine powder was extracted under the 


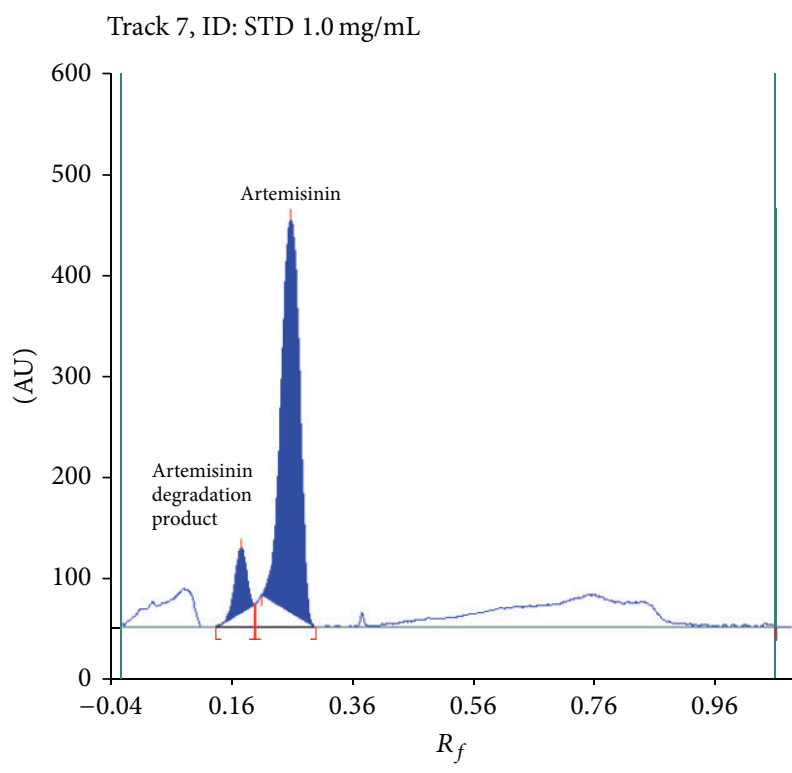

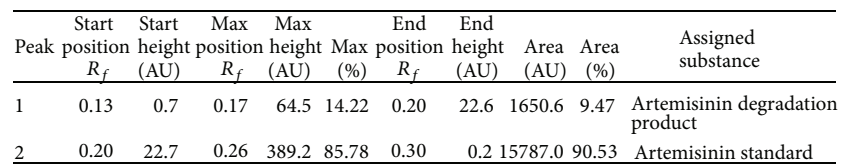

FIGURE 3: Chromatogram showing degradation in artemisinin standard (prepared in methanol) after two months of storage at room temperature during rainy season.

influence of microwave energy using $n$-hexane, benzene, toluene, chloroform, methylene dichloride, ethyl acetate, acetone, methanol, and acetonitrile. Extraction parameters (160 watts, $120 \mathrm{~s}, 10 \mathrm{~mL}$ per extraction cycle, two extraction cycles, and cleanup with $2 \mathrm{~mL}$ of corresponding solvent at the end of second cycle of extraction) for microwave-assisted extraction (MAE) were the same for every solvent. The extract thus obtained was evaporated in vacuo and redissolved in $5 \mathrm{~mL}$ methanol. $10 \mu \mathrm{L}$ of these test solutions was used for quantification purpose.

2.8. Optimization of Mobile Phase. Mobile phase for the high-performance thin-layer chromatographic separation of artemisinin present in plant extract was optimized using different binary mixtures (except for methylene dichloride) of few solvents. Five different thin-layer plates of size $20 \times$ $100 \mathrm{~mm}$ were taken and parameters remain common for every plate; for example, application position and solvent front were $10 \mathrm{~mm}$ and $95 \mathrm{~mm}$ above from the base of thinlayer plate, respectively. Height of mobile phase was fixed to $3 \mathrm{~mm}$ in all applications, since we used the same volume in every case, for the calculation of flow constant. Other thinlayer parameters were also calculated for every case such as $R_{f}$, time of thin-layer development, flow constant, and number of theoretical plates (Table 1). Room temperature was $25.0 \pm 2.0^{\circ} \mathrm{C}$ at the time of optimization. Eluted artemisinin spots in all the five cases were subjected to densitometric evaluation to find out base-line separation and peak purity

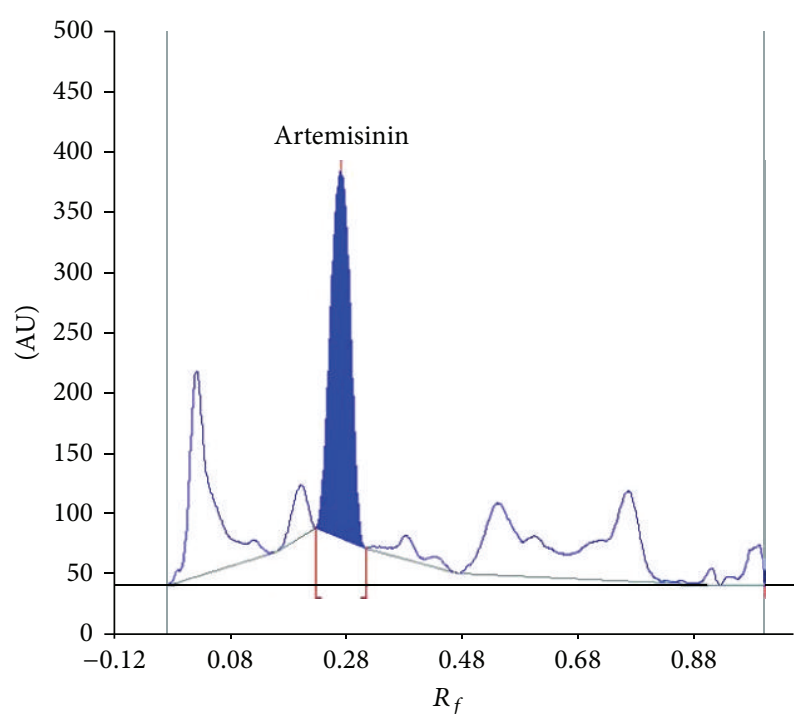

FIGURE 4: HPTLC chromatogram showing artemisinin $\left(R_{f}=0.28\right)$ separation.

status. Densitometric evaluation of artemisinin separation over TLC through $n$-hexane : ethyl acetate $(75: 25, \mathrm{v} / \mathrm{v})$ and $n$ hexane : diethyl ether $(50: 50, \mathrm{v} / \mathrm{v})$ was showing peak purity of up and down slopes, not less than 0.999 and 0.998 , respectively, which is indicative of better separation with no interfering neighboring peaks (Table 1$)$. We, therefore, had selected $n$-hexane: ethyl acetate $(75: 25, \mathrm{v} / \mathrm{v})$ for further development. Alternatively, as per the peak purity data, $n$ hexane : diethyl ether $(50: 50, \mathrm{v} / \mathrm{v})$ may also be used for the purpose.

2.9. Chromatographic Analysis. Thin-layer chromatography was performed on aluminum backed HPTLC plates $\left(60 \mathrm{~F}_{254}\right.$, E. Merck, Germany, $200 \times 200 \mathrm{~mm}) .10 \mu \mathrm{L}$ of test and standard sample spots were applied via CAMAG's Linomat 5 as $6.0 \mathrm{~mm}$ wide bands at the height of $10 \mathrm{~mm}$ from base; spots were simultaneously dried with $\mathrm{N}_{2}$ gas supply onto HPTLC plates. Plates were developed, in a CAMAG twin trough chamber of size more than $200 \times 200 \mathrm{~mm}$, at $95 \mathrm{~mm}$ height from the base using $n$-hexane : ethyl acetate $(75: 25, \mathrm{v} / \mathrm{v})$ as mobile phase. Room temperature and relative humidity at the time of development were $25.0 \pm 2^{\circ} \mathrm{C}$ and $45 \pm 2 \%$, respectively. Plates were air-dried for complete evaporation of mobile phase and derivatized with anisaldehyde-sulphuric acid reagent followed by heating to $110^{\circ} \mathrm{C}$ for $10-15$ minutes to visualize pink-colored spots of artemisinin. This plate was stabilized at room temperature for 30 minutes and scanned using CAMAG's TLC scanner 3 equipped with winCATS software in absorption-reflection detection mode at $540 \mathrm{~nm}$ using tungsten lamp. HPTLC chromatogram of artemisinin separation has been shown in Figure 4. Additionally, a TLC photograph of commercial samples analysis is attached to show background color and spots of artemisinin, after postchromatographic derivatization (Figure 5). 


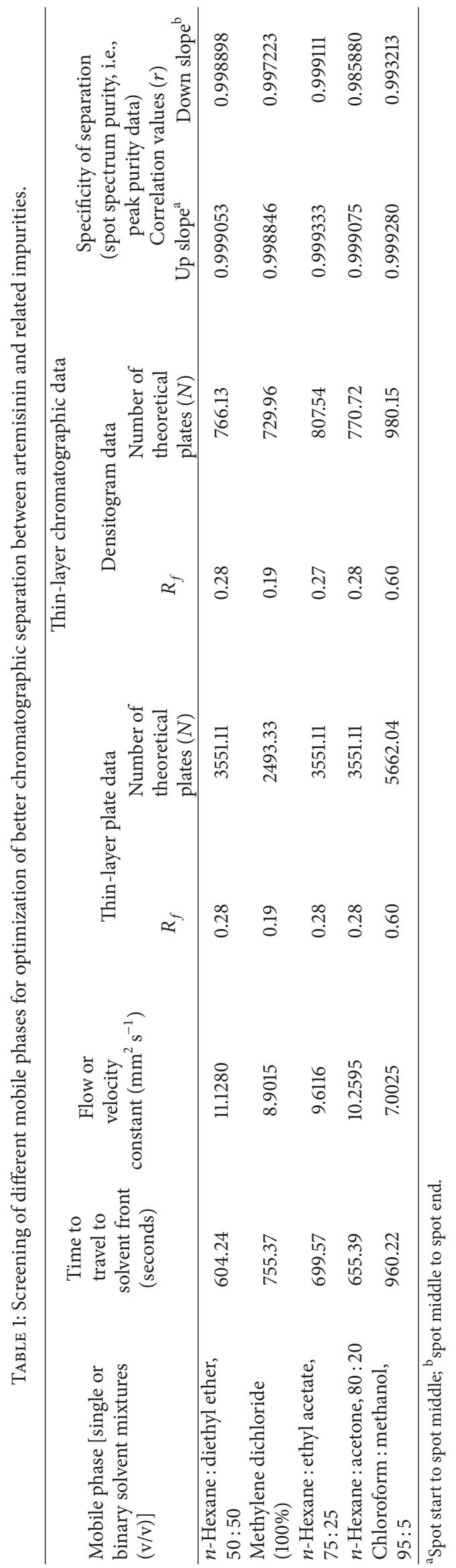




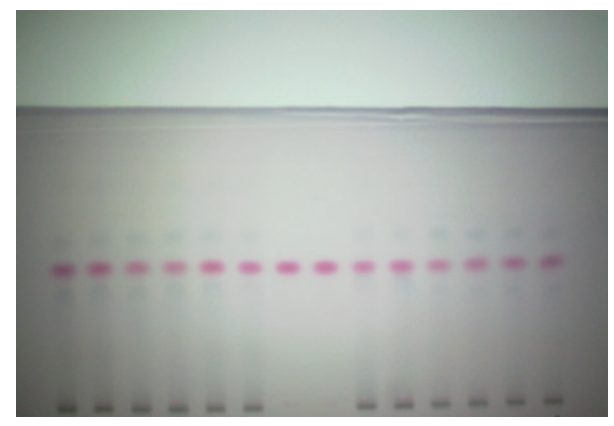

FIGURE 5: TLC image of commercial sample analysis for artemisinin determination.

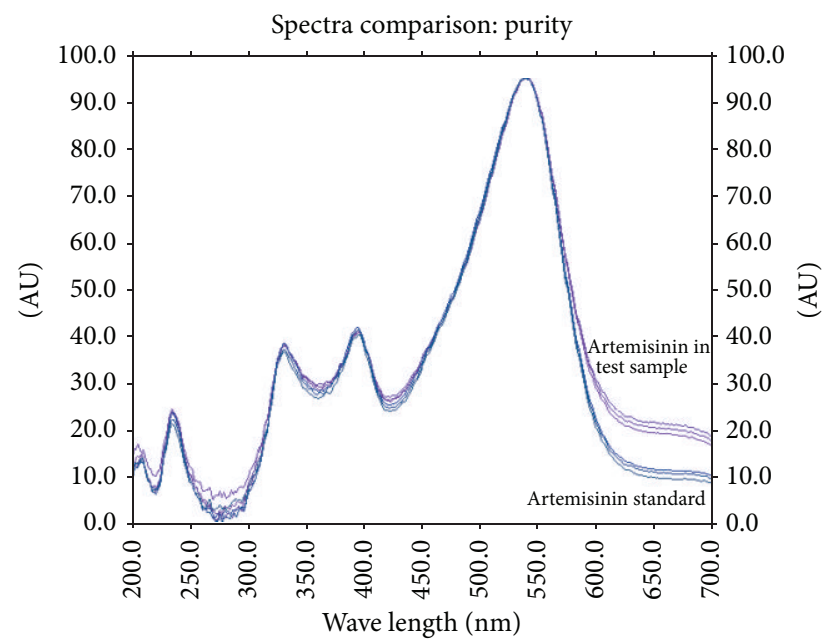

FIGURE 6: Overlay ultraviolet absorption spectra (up and down slopes of standard and test artemisinin spots eluted onto TLC) of artemisinin showing peak purity and $\lambda_{\text {max. }}$ at $540 \mathrm{~nm}$.

\subsection{Method Validation}

2.10.1. System Suitability. The system suitability test is used to ensure reproducibility of the equipment. The test was carried out by applying $2 \mu \mathrm{L}$ of the standard solution of artemisinin $\left(1.0 \mathrm{mg} \mathrm{mL}^{-1}\right)$ and $10 \mu \mathrm{L}$ of the standard solution of artemisinin $\left(0.20 \mathrm{mg} \mathrm{mL}^{-1}\right)$ six times each. The RSD was found to be less than $2 \%$.

2.10.2. Specificity. The developed HPTLC-visible method was found to be specific as no interfering peak(s) was found during detection of artemisinin. Peaks of artemisinin eluted on to HPTLC plate were found to be pure, which was also evidenced by overlapping ultraviolet absorption spectra of up and down slopes of the peak as shown in Figure 6. Correlation coefficients of peak [(start, middle) and (middle, end)] were not less than 0.99 and 0.99 , respectively.

2.10.3. Limits of Detection and Quantitation (LOD and LOQ). Limits of detection and quantitation were determined by spotting increasing amounts $(10-140 \mathrm{ng} ; n=2)$ of standard artemisinin solution of concentration $10 \mu \mathrm{g} \mathrm{mL}^{-1}$, that is,
$10 \mathrm{ng} \mu \mathrm{L}^{-1}$ (1 mg of artemisinin per $100 \mathrm{~mL}$ ), until the average responses were 3 and 10 times of noise for LOD and LOQ, respectively. LOD and LOQ were found to be 40 and $80 \mathrm{ng} \mathrm{spot}^{-1}$, respectively.

2.10.4. Linearity Range. The linearity of the artemisinin calibration plot was evaluated on seven-point scale by spotting increasing amounts of the artemisinin working standard solution of $200 \mu \mathrm{g} \mathrm{mL} L^{-1}$, starting from 400 to $2800 \mathrm{ng} \mathrm{spot}{ }^{-1}$. The method showed good linearity in the given range with a correlation coefficient of $0.99754\left(r^{2}=0.99509\right)$ and the linear regression equation was $Y=4.749 X+1030(s d v=$ $3.66 \%$ ) (Figure 2).

2.10.5. Precision. The precision of the method was determined by three replications of each sample. The precision (\%RSD) of the replications was in between 0.15 and 3.28\%, which is indicative of a precise method (Tables 3 and 4).

2.10.6. Accuracy (Recovery Study). Accuracy of the method was studied using the method of standard addition. Standard artemisinin solutions were added to the extract of the leaves of $A$. annua and the percentage recovery was determined at three different levels. For recovery study, a test extract with known artemisinin content was taken; now $2 \mathrm{~mL}$ of this extract was pipetted out in three different test tubes. Now $4 \mathrm{~mL}, 3 \mathrm{~mL}$, and $3 \mathrm{~mL}$ of freshly prepared standard artemisinin solutions of concentrations $1.0 \mathrm{mg} \mathrm{mL}^{-1}$, $1.5 \mathrm{mg} \mathrm{mL}^{-1}$, and $2.0 \mathrm{mg} \mathrm{mL}^{-1}$ were added to test tubes 1,2 , and 3 , respectively. The mixed solutions thus prepared were then evaluated chromatographically. The artemisinin contents were determined and the percent recoveries were calculated. The results of recovery analysis are shown in Table 2.

2.10.7. Robustness. Robustness of the method was determined by performing small variations in mobile phase ratio, height of plate development, and TLC tank saturation time. The results indicated insignificant differences in assay and were thus indicative of a robust method.

2.10.8. Calculation of Flow Constant [57-59]. The flow or velocity constant $(k)$ is a measure of the migration rate of the solvent front. It is an important parameter for TLC users and can be used to calculate, for example, development times with different separation distances, provided that the sorbent, solvent system, chamber type, and temperature remain constant. The flow constant is given by the following equation:

$$
k=\frac{Z_{F}^{2}}{t},
$$

where $k$ is flow constant $\left(\mathrm{mm}^{2} / \mathrm{s}\right), Z_{F}$ is distance between the solvent front and the solvent level (mm), and $t$ is the development time (seconds). The flow constant as calculated for different mobile phases has been shown in Table 1 . 
TABLE 2: Recovery study data of artemisinin.

\begin{tabular}{|c|c|c|c|c|}
\hline $\begin{array}{l}\text { Artemisinin present } \\
\text { in test solution } \\
\left(\mu \mathrm{g} \mathrm{mL}^{-1}\right)\end{array}$ & $\begin{array}{l}\text { Amount and volume } \\
\text { of artemisinin } \\
\text { standard added } \\
\left(\mu \mathrm{g} \mathrm{mL}^{-1}\right)\end{array}$ & $\begin{array}{c}\text { Amount of } \\
\text { artemisinin in mixed } \\
\text { solution } \\
\left(\mu \mathrm{g} \mathrm{mL}^{-1}\right)\end{array}$ & $\begin{array}{l}\text { Amount of } \\
\text { artemisinin detected } \\
\left(\mu \mathrm{g} \mathrm{mL}^{-1}\right)\end{array}$ & Recovery (\%) \\
\hline $634.97(2 \mathrm{~mL})$ & $1000.00(4 \mathrm{~mL})$ & 878.32 & 917.68 & 104.48 \\
\hline $634.97(2 \mathrm{~mL})$ & $1500.00(3 \mathrm{~mL})$ & 1153.98 & 1138.53 & 98.66 \\
\hline $634.97(2 \mathrm{~mL})$ & $2000.00(3 \mathrm{~mL})$ & 1453.98 & 1081.69 & 74.39 \\
\hline
\end{tabular}

TABLE 3: Screening of solvents for better extraction of artemisinin through application of microwaves.

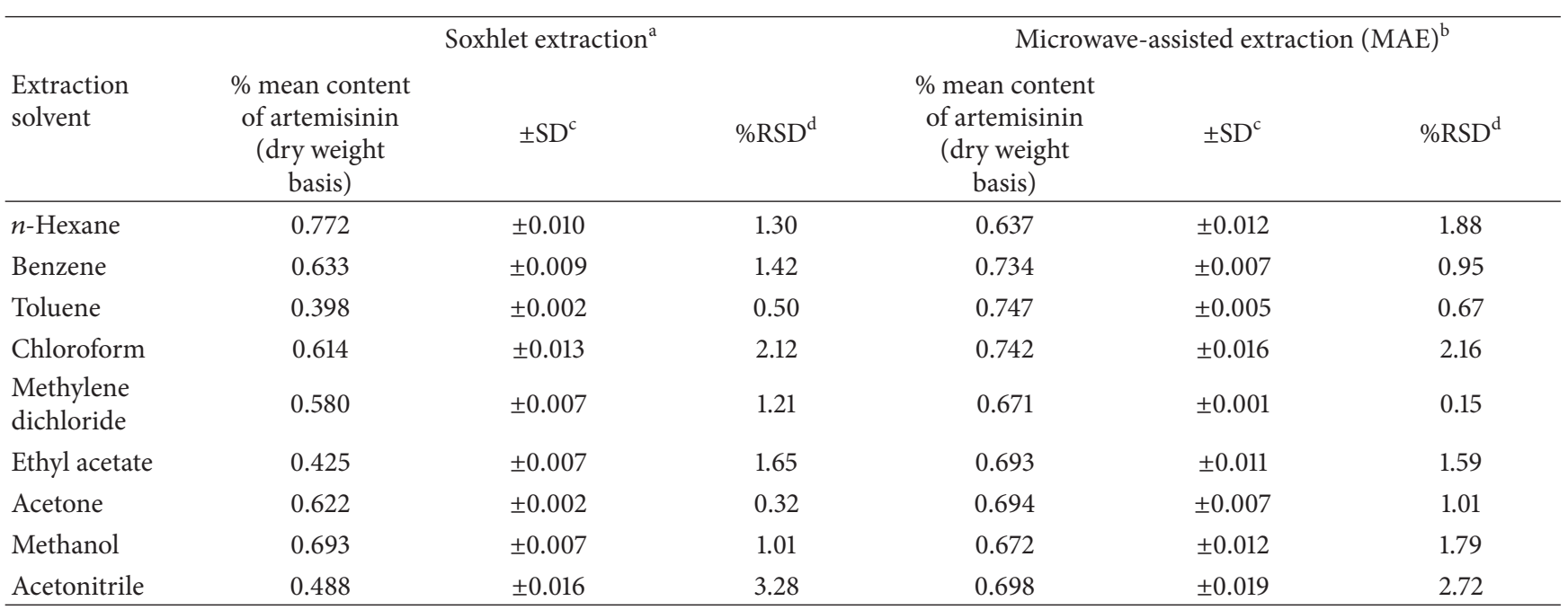

${ }^{\text {a }}$ Soxhlet extractions were performed over a water bath.

${ }^{\mathrm{b}}$ MAE conditions: $100 \mathrm{mg}, 14$ mesh, 160 watts, 120 seconds, $10 \mathrm{~mL} \times 2$ cycles of extraction, and cleanup with $2 \mathrm{~mL}$.

${ }^{\mathrm{c}}$ Standard deviation.

${ }^{\mathrm{d}}$ Relative standard deviation.

2.10.9. Calculation of Plate Efficiency (N). Plate efficiency, also known as number of theoretical plates, was calculated for the described method by the following equation [58-61]:

$$
N=\frac{16 \times l \times z}{w^{2}}
$$

where $l$ is the position of solvent front from spot application position (in $\mathrm{mm}$ ), $z$ is the distance traveled by the analyte onto plate (in $\mathrm{mm}$ ), and $w$ is the width of spot (in $\mathrm{mm}$ ) to the direction of mobile phase. The plate efficiency for artemisinin is shown in Table 1.

\section{Results and Discussion}

3.1. Screening of Solvents. Solvents from low polar to high polar ( $n$-hexane, benzene, toluene, methylene dichloride, chloroform, ethyl acetate, acetone, methanol, and acetonitrile) were used for the screening of artemisinin extraction using hot soxhlet extraction (solvent volume: $170 \mathrm{~mL}$ solvent, extraction time: $6 \mathrm{~h}$ ) and microwave irradiation-assisted extraction (MAE conditions: 160 watts, $120 \mathrm{~s}, 10 \mathrm{~mL}$ per extraction cycle, two extraction cycles, and cleanup with $2 \mathrm{~mL}$ of corresponding solvent at the end of second cycle of extraction). Results of hot soxhlet and microwave-assisted extractions are summarized in Table 3.
Soxhlet extraction showed good recovery of artemisinin with $n$-hexane (artemisinin content $0.772 \%$ ) in comparison to chloroform, methylene dichloride, ethyl acetate, and acetone; we, therefore, have selected soxhlet extraction with $n$-hexane as control for this study and further optimization results will be compared with control value of artemisinin content, that is, $0.772 \%$, while other high boiling solvents could not yield that much artemisinin content due to lesser numbers of leaching which occurred during $6 \mathrm{~h}$. In contrast, MAE showed good recovery of artemisinin with high boiling solvents like benzene $(0.734 \%)$, toluene $(0.747 \%)$, and acetonitrile (0.698\%), although chloroform also yielded good artemisinin content $(0.742 \%)$ with MAE, which is in accordance with the study by Hao et al. [54]. Ethyl acetate, acetone, and acetonitrile produced almost similar results with MAE, while MAE with methanol was difficult due to frequent bumping and, therefore, a big volume and tall-form vial selected for errorfree extraction with methanol through MAE. Methanol yielded $0.672 \%$ artemisinin with MAE and $0.693 \%$ with soxhlet extraction. Pulverized leaves float over chloroform due to lesser bulk density; therefore, we felt difficulty in transfer of chloroform extract from extraction vessel to test tube and in recollection of leaves in extraction vial, for second cycle of extraction and similarly for cleanup step. Due to this reason, chloroform was not preferred. 
TABLE 4: Finalization of solvent and extraction conditions for microwave-assisted extraction of artemisinin.

\begin{tabular}{|c|c|c|c|}
\hline \multirow{2}{*}{ Extraction solvent } & \multicolumn{3}{|c|}{ Microwave-assisted extraction $(\mathrm{MAE})^{\mathrm{a}}$} \\
\hline & $\%$ mean content of artemisinin (dry wt. basis) & \pm Standard deviation & $\% \mathrm{RSD}^{\mathrm{b}}$ \\
\hline Benzene & 0.809 & \pm 0.017 & 2.10 \\
\hline Toluene & 0.816 & \pm 0.016 & 1.96 \\
\hline
\end{tabular}

${ }^{a}$ MAE conditions: $100 \mathrm{mg}, 14$ mesh, 160 watts, 120 seconds, $10 \mathrm{~mL} \times 3$ cycles of extraction, and cleanup with $2 \mathrm{~mL}$.

${ }^{\mathrm{b}}$ Relative standard deviation.

TABLE 5: Artemisinin content in different parts of whole plant.

\begin{tabular}{lccc}
\hline Plant part & \% mean artemisinin content (dry wt. basis) & \pm Standard deviation & \%RSD $^{\dagger}$ \\
\hline Leaves & 0.776 & 0.008 & 1.031 \\
Main stem & 0.030 & 0.002 & 6.667 \\
Branches (excluding main stem) & 0.421 & 0.008 & 1.900 \\
Main stem + side branches (mixed sample) & 0.239 & 0.002 & - \\
Roots & nd & - \\
\hline
\end{tabular}

${ }^{\dagger}$ Relative standard deviation; ${ }^{\text {nd }}$ not detected.

As high boiling solvents like benzene, toluene, and lowboiling chloroform have given similar results, these were selected for further optimization of MAE conditions, but, as per previous reports without stabilization, chloroform degrades to form small amounts of free radicals, hydrochloric acid, and phosgene, which are extremely toxic [62-64]:

$$
\mathrm{CHCl}_{3}+\mathrm{O}_{2} \longrightarrow \underset{\text { Phosgene }}{\mathrm{Co}(\mathrm{Cl})_{2}}
$$

The Bhopal tragedy in December, 1984, wherein leakage of methyl isocyanate $\left(\mathrm{CH}_{3}-\mathrm{N}=\mathrm{C}=\mathrm{O}\right)$ and phosgene from Union Carbide pesticide plant took an unprecedented toll of over 2000 human lives and thousands of animals, is a solemn reminder of the duty of industry and government in protecting the population from atmospheric pollution. Chloroform was also banned by Food and Drug Administration of America in 1976. Thus, we have omitted chloroform and chosen benzene and toluene for further optimization of MAE conditions as both of the solvents yielded the highest artemisinin content in comparison with other solvents.

Hao et al. [54] had not applied few commonly available solvents like benzene, toluene, methylene dichloride, ethyl acetate, acetone, methanol, and acetonitrile, whereas we have applied all these solvents for the extraction of artemisinin under microwave irradiation (Tables 3 and 4).

3.2. Finalization of Solvent for Extraction. For further optimization of MAE conditions, we had taken three extraction cycles instead of two with selected solvents after screening, that is, benzene and toluene. On increasing number of extraction cycles from two to three, benzene and toluene recovered $0.809 \%$ and $0.816 \%$ of artemisinin, respectively (Table 4 ). This is $4.79 \%$ and $5.69 \%$ more than that of our selected control artemisinin content (i.e., $0.772 \%$ ). However, Hao et al. [54] described the best conditions for microwave-assisted extraction of artemisinin as follows: number 6 extraction solvent oil, diameter of raw materials less than $0.125 \mathrm{~mm}$, and 12 minutes of microwave irradiation. But they recovered only $0.237 \%$ of artemisinin (\% recovery of artemisinin
$=0.237 / 0.282 \times 100=84.04 \%)$ than that present in control sample $(0.282 \%$ artemisinin $)$, which is approximately $15.96 \%$ less than that present in raw material.

So, our optimized MAE conditions were $100 \mathrm{mg}, 14 \mathrm{mesh}$, 160 watts, 120 seconds, $10 \mathrm{~mL} \times 3$ cycles of extraction, and cleanup with $2 \mathrm{~mL}$ (Table 4 ). As shown in Table 3, toluene extracted the highest artemisinin content from dried $A$. annua leaves under microwave irradiation. Extraction of artemisinin using benzene as solvent also produces almost similar results, so, as per availability, any of the solvents (i.e., benzene or toluene) may be utilized for the extraction purpose, although our recommendation is toluene, which is safer than benzene in terms of carcinogenicity.

3.3. Artemisinin Content in Different Parts of Plant. Artemisinin content in the different parts (leaves, branches, main stem, and roots) of the plant was determined using soxhlet extraction with $n$-hexane. Artemisinin content was found to be present in the decreasing order of artemisinin (Table 5):

leaves $>$ side branches $>$ main stem.

However, no artemisinin was detected in root extract or artemisinin may be below the detection limit in root extract of $A$. annua. These results are in accordance with the previous studies $[25,65]$. The leaves from the same plant may have different artemisinin contents according to their localization along the stem: upper leaves contain significantly more artemisinin than middle and lower ones [56], which was also verified by us using fresh green leaves from top, middle, and base of the single plant. Artemisinin content was then evaluated using the procedure of fresh leaves extraction reported previously [31]. The artemisinin content, in plant, also varies during the season. Furthermore, the genetic basis and environmental factors such as temperature or nutrient availability further influence the artemisinin content in the plant [66]. 


\section{Conclusion}

The developed microwave-assisted extraction and HPTLC method are not only rapid but also reliable for analysis of artemisinin in Artemisia annua. This method will be useful for monitoring of artemisinin during different stages of plant growth and thereby determination of time of harvest, in plant variety development through selection of plants with higher artemisinin content, and for routine industrial batch analysis for evaluation of the commercial value of plant material. The method also includes calculation of flow constant and the number of theoretical plates as components of validation. Different parts of the plant (leaves, branches, main stem, and roots) were analyzed for the artemisinin content, but the artemisinin content was found higher in the leaves with respect to branches and the main stem; however, artemisinin was not detected in roots.

\section{Disclaimer}

Readers are advised to use only chemical-safe microwave apparatus and never to use domestic/kitchen microwave oven for any type of chemical processing. The authors would not be responsible for any loss that occurred by the use of the method described or equipment used in this study.

\section{Conflict of Interests}

This research paper is the part of the Ph.D. degree of one of the authors, Himanshu Misra, and is not intended for any financial gains. Additionally, no competing interests exist among CAMAG, Büchi, or any other scientific equipment companies.

\section{Acknowledgment}

Authors are very thankful to the management of Ipca Laboratories Limited for valuable support and facilities during the course of work.

\section{References}

[1] W. H. Wernsdorfer, "Epidemiology of drug resistance in malaria," Acta Tropica, vol. 56, no. 2-3, pp. 143-156, 1994.

[2] P. J. De Vries and T. K. Dien, "Clinical pharmacology and therapeutic potential of artemisinin and its derivatives in the treatment of malaria," Drugs, vol. 52, no. 6, pp. 818-836, 1996.

[3] E. Gkrania-Klotsas and M. L. Lever, "An update on malaria prevention, diagnosis and treatment for the returning traveller," Blood Reviews, vol. 21, no. 2, pp. 73-87, 2007.

[4] A. Singh, V. K. Kaul, V. P. Mahajan, A. Singh, L. N. Misra, and R. S. Thakur, "Introduction of Artemisia annua in India and isolation of artemisinin, a promising antimalarial drug," Indian Journal of Pharmaceutical Sciences, vol. 48, no. 5, pp. 137-138, 1986.

[5] CIMAP, "Development of Agro-technologies for Artemisia annua for antimalarial drug artemisinin," Annual Project Report 1986-87, Central Institute for Medicinal and Aromatic Plants, Lucknow, India.
[6] CIMAP, "Development of Agro-technologies for Artemisia annua for antimalarial drug artemisinin," Annual Project Report 1988-89, Central Institute for Medicinal and Aromatic Plants, Lucknow, India.

[7] S. K. Gupta, P. Singh, P. Bajpai et al., "Morphogenetic variation for artemisinin and volatile oil in Artemisia annua," Industrial Crops and Products, vol. 16, no. 3, pp. 217-224, 2002.

[8] S. Kumar, S. K. Gupta, M. M. Gupta et al., "Method for maximization of artemisinin production of the plant Artemisia annua L," Indian Patent No. NF-122/2000, US 09/538, 892, 2000, 6,393,763, 2002.

[9] P. C. Allen, J. Lydon, and H. D. Danforth, "Effects of components of Artemisia annua on Coccidia infections in Chickens," Poultry Science, vol. 76, no. 8, pp. 1156-1163, 1997.

[10] H. A. Arab, S. Rahbari, A. Rassouli, M. H. Moslemi, and F. Khosravirad, "Determination of artemisinin in Artemisia sieberi and anticoccidial effects of the plant extract in broiler chickens," Tropical Animal Health and Production, vol. 38, no. 6, pp. 497503, 2006.

[11] R. S. Bhakuni, D. C. Jain, R. P. Sharma, and S. Kumar, "Secondary metabolites of Artemisia annua and their biological activity," Current Science, vol. 80, no. 1, pp. 35-48, 2001.

[12] T. Efferth, M. R. Romero, D. G. Wolf, T. Stamminger, J. J. G. Marin, and M. Marschall, "The antiviral activities of artemisinin and artesunate," Clinical Infectious Diseases, vol. 47, no. 6, pp. 804-811, 2008.

[13] A. C. Beekman, P. K. Wierenga, H. J. Woerdenbag et al., "Artemisinin-derived sesquiterpene lactones as potential antitumour compounds: cytotoxic action against bone marrow and tumour cells," Planta Medica, vol. 64, no. 7, pp. 615-619, 1998.

[14] S. Oh, B. J. Kim, N. P. Singh, H. Lai, and T. Sasaki, "Synthesis and anti-cancer activity of covalent conjugates of artemisinin and a transferrin-receptor targeting peptide," Cancer Letters, vol. 274, no. 1, pp. 33-39, 2009.

[15] J. A. Levy, L. F. Marins, and A. Sanchez, "Gene transfer technology in aquaculture," Hydrobiologia, vol. 420, no. 1-3, pp. 91-94, 2000.

[16] A. Mannan, N. Shaheen, W. Arshad, R. A. Qureshi, M. Zia, and B. Mirza, "Hairy roots induction and artemisinin analysis in Artemisia dubia and Artemisia indica," African Journal of Biotechnology, vol. 7, no. 18, pp. 3288-3292, 2008.

[17] X. C. He, M. Y. Zeng, G. F. Li, and Z. Liang, "Callus induction and regeneration of plantlets from Artemisia annua and changes of Qinghaosu contents," Acta Botanica Sinica, vol. 25, no. 1, pp. 87-90, 1983.

[18] D. P. Fulzele, A. T. Sipahimalani, and M. R. Heble, "Tissue cultures of Artemisia annua: organogenesis and artemisinin production," Phytotherapy Research, vol. 5, no. 4, pp. 149-153, 1991.

[19] M. B. Qin, G. Z. Li, H. C. Ye, and G. F. Li, "Induction of hairy root from Artemisia annua with Agrobacterium rhizogenes and its culture in vitro," Acta Botanica Sinica, vol. 36, pp. 165-170, 1994.

[20] A. Giri, S. T. Ravindra, V. Dhingra, and M. L. Narasu, "Influence of different strains of Agrobacterium rhizogenes on induction of hairy roots and artemisinin production in Artemisia annua," Current Science, vol. 81, no. 4, pp. 378-382, 2001.

[21] B. M. Aryanti, T. M. Ermayanti, and I. Mariska, "Production of antileukemic agent in untransformed and transformed root cultures of Artemisia cina," Annales Bogorienses, vol. 8, pp. 11$16,2001$. 
[22] M. Zia and M. F. Chaudhary, "Effect of growth regulators and amino acids on artemisinin production in the callus of Artemisia absinthium," Pakistan Journal of Botany, vol. 39, no. 3, pp. 799-805, 2007.

[23] R. X. Tan, W. F. Zheng, and H. Q. Tang, "Biologically active substances from the genus Artemisia," Planta Medica, vol. 64, no. 4, pp. 295-302, 1998.

[24] E. Hsu, "The history of qing hao in the Chinese material medica," Transactions of the Royal Society of Tropical Medicine and Hygiene, vol. 100, no. 6, pp. 505-508, 2006.

[25] A. Mannan, I. Ahmed, W. Arshad et al., "Survey of artemisinin production by diverse Artemisia species in northern Pakistan," Malaria Journal, vol. 9, no. 1, article 310, 2010.

[26] J. Suresh, K. Mruthunjaya, N. Paramakrishnan, and M. N. Naganandhini, "Determination of artemisinin in Artemisia abrotanum and Artemisia pallens by LC/MS method," International Journal of Current Pharmaceutical Research, vol. 3, no. 1, pp. 49-52, 2011.

[27] A. G. Namdeo, K. R. Mahadik, and S. S. Kadam, "Antimalarial drug-Artemisia annua," Pharmacognosy Magazine, vol. 2, no. 6, pp. 106-111, 2006.

[28] E.-M. B. El-Naggar, M. Azazi, E. Švajdlenka, and M. Žemlička, "Artemisinin from minor to major ingredient in Artemisia annua cultivated in Egypt," Journal of Applied Pharmaceutical Science, vol. 3, no. 8, pp. 116-123, 2013.

[29] D. L. Klayman, A. J. Lin, N. Acton et al., "Isolation of artemisinin (qinghaosu) from Artemisia annua growing in the United States," Journal of Natural Products, vol. 47, no. 4, pp. 715-717, 1984.

[30] M. Gabriëls and J. Plaizier-Vercammen, "Development of a reversed-phase thin-layer chromatographic method for artemisinin and its derivatives," Journal of Chromatographic Science, vol. 42, no. 7, pp. 341-347, 2004.

[31] M. M. Gupta, D. C. Jain, R. K. Verma, and A. P. Gupta, "A rapid analytical method for the estimation of artemisinin in Artemisia annua," Journal of Medicinal and Aromatic plant sciences, vol. 18, no. 1, pp. 5-6, 1996.

[32] J. A. Marchese, V. L. G. Rehder, and A. Sartoratto, "Quantification of artemisinin in Artemisia annua L A comparison of thin layer chromatography with densitometric detection and high performance liquid chromatography with UV detection," Revista Brasileira de Plantas Medicinais, vol. 4, pp. 81-87, 2001.

[33] M. Gabriëls and J. A. Plaizier-Vercammen, "Densitometric thinlayer chromatographic determination of artemisinin and its lipophilic derivatives, artemether and arteether," Journal of Chromatographic Science, vol. 41, no. 7, pp. 359-366, 2003.

[34] P. Bhandari, A. P. Gupta, B. Singh, and V. K. Kaul, "Simultaneous densitometric determination of artemisinin, artemisinic acid and arteannuin-B in Artemisia annua using reversed-phase thin layer chromatography," Journal of Separation Science, vol. 28, no. 17, pp. 2288-2292, 2005.

[35] H. N. ElSohly, E. M. Croom, and M. A. ElSohly, "Analysis of the antimalarial sesquiterpene artemisinin in Artemisia annua by high-performance liquid chromatography (HPLC) with postcolumn derivatization and ultraviolet detection," Pharmaceutical Research, vol. 4, no. 3, pp. 258-260, 1987.

[36] B. L. Singh, D. V. Singh, R. K. Verma, M. M. Gupta, D. C. Jain, and S. Kumar, "Simultaneous determination of antimalarial drugs using reversed phase high-performance liquid chromatography diode-array detection," Journal of Medicinal and Aromatic Plant Sciences, vol. 22-23, no. 4A-1A, pp. 17-20, 2000 .
[37] G.-P. Qian, Y.-W. Yang, and Q.-L. Ren, "Determination of artemisinin in Artemisia annua L. by reversed phase HPLC," Journal of Liquid Chromatography \& Related Technologies, vol. 28, no. 5, pp. 705-712, 2005.

[38] N. Erdemoglu, I. Orhan, M. Kartal, N. Adýgüzel, and B. Bani, "Determination of artemisinin in selected Artemisia L. species of Turkey by reversed phase HPLC," Records of Natural Products, vol. 1, no. 2-3, pp. 36-43, 2007.

[39] N. Acton, D. L. Klayman, and I. J. Rollman, "Reductive electrochemical HPLC assay for artemisinin (Qinghaosu)," Planta Medica, vol. 51, no. 5, pp. 445-446, 1985.

[40] J. F. S. Ferreira, D. J. Charles, K. Wood, J. Janick, and J. E. Simon, "A comparison of gas chromatography and high performance liquid chromatography for artemisinin analyses," Phytochemical Analysis, vol. 5, no. 3, pp. 116-120, 1994.

[41] B. A. Avery, K. K. Venkatesh, and M. A. Avery, "Rapid determination of artemisinin and related analogues using highperformance liquid chromatography and an evaporative light scattering detector," Journal of Chromatography B: Biomedical Sciences and Applications, vol. 730, no. 1, pp. 71-80, 1999.

[42] X.-R. Hu and F.-H. She, "Determination of artemisinin content in Artemisia annua from different regions by HPLCevaporative light scattering detection," Xiandai Shipin Yu Yaopin Zazhi, vol. 16, pp. 34-36, 2006.

[43] C. A. Peng, J. F. S. Ferreira, and A. J. Wood, "Direct analysis of artemisinin from Artemisia annua L. using high-performance liquid chromatography with evaporative light scattering detector, and gas chromatography with flame ionization detector," Journal of Chromatography A, vol. 1133, no. 1-2, pp. 254-258, 2006.

[44] C.-Z. Liu, H.-Y. Zhou, and Y. Zhao, "An effective method for fast determination of artemisinin in Artemisia annua L. by high performance liquid chromatography with evaporative light scattering detection," Analytica Chimica Acta, vol. 581, no. 2, pp. 298-302, 2007.

[45] A. Amponsaa-Karikari, N. Kishikawa, Y. Ohba, K. Nakashim, and N. Kuroda, "Determination of artemisinin in human serum by high-performance liquid chromatography with on-line UV irradiation and peroxyoxalate chemiluminescence detection," Biomedical Chromatography, vol. 20, no. 11, pp. 1157-1162, 2006.

[46] J. Xing, H. Yan, S. Zhang, G. Ren, and Y. Gao, "A highperformance liquid chromatography/tandem mass spectrometry method for the determination of artemisinin in rat plasma," Rapid Communications in Mass Spectrometry, vol. 20, no. 9, pp. 1463-1468, 2006.

[47] M. Wang, C. Park, Q. Wu, and J. E. Simon, "Analysis of artemisinin in Artemisia annua L. by LC-MS with selected ion monitoring," Journal of Agricultural and Food Chemistry, vol. 53, no. 18, pp. 7010-7013, 2005.

[48] B. Huang and C. Yao, "Determination of artemisinin by capillary electrophoresis with conductivity detection," Fenxi Ceshi Xuebao, vol. 25, pp. 109-111, 2006.

[49] H. J. Woerdenbag, N. Pras, R. Bos, J. F. Visser, H. Hendriks, and T. M. Malingre, "Analysis of artemisinin and related sesquiterpenoids from Artemisia annua by combined gas chromatography-mass spectrometry," Phytochemical Analysis, vol. 2, no. 5, pp. 215-219, 1991.

[50] A. T. Sipahimalani, D. P. Fulzele, and M. R. Heble, "Rapid method for the detection and determination of artemisinin by gas chromatography," Journal of Chromatography A, vol. 538, no. 2, pp. 452-455, 1991. 
[51] J. F. S. Ferreira and J. Janick, "Immunoquantitative analysis of artemisinin from Artemisia annua using polyclonal antibodies," Phytochemistry, vol. 41, no. 1, pp. 97-104, 1996.

[52] T. V. Sreevidya and B. Narayana, "Spectrophotometric determination of artemisinin and dihydroartemisinin," Indian Journal of Chemical Technology, vol. 15, no. 1, pp. 59-62, 2008.

[53] P. Christen and J.-L. Veuthey, "New trends in extraction, identification and quantification of artemisinin and its derivatives," Current Medicinal Chemistry, vol. 8, no. 15, pp. 1827-1839, 2001.

[54] J.-Y. Hao, W. Han, S.-D. Huang, B.-Y. Xue, and X. Deng, "Microwave-assisted extraction of artemisinin from Artemisia annua L," Separation and Purification Technology, vol. 28, no. 3, pp. 191-196, 2002.

[55] S. Kumar, S. Banerjee, S. Dwivedi et al., "Registration of Jeevanraksha and suraksha varieties of the antimalarial medicinal plant Artemisia annua," Journal of Medicinal and Aromatic Plant Sciences, vol. 21, no. 1, pp. 47-48, 1999.

[56] Per Diemer (FAO consultant), WHO and EcoPort version by Peter Griffee (FAO), and Contributor: Peter Griffee, QA and TEM, "Artemisia annua; the plant, production and processing and medicinal applications," 2013, http://www.mmv.org/sites/ default/files/uploads/docs/artemisinin/2007_event/12_DiemerGriffee_Artemisia_annuapaper.pdf.

[57] E. Hahn-Deinstrop, Applied Thin-Layer Chromatography: Best Practice and Avoidance of Mistakes, Wiley-VCH Verlag $\mathrm{GmbH}$ \& Co. KgaA, Weinheim, Germany, 2nd edition, 2007.

[58] H. Misra, B. K. Mehta, and D. C. Jain, "Comparison of extraction conditions and HPTLC-UV method for determination of quinine in different extracts of Cinchona Species bark," Records of Natural Products, vol. 2, no. 4, pp. 107-115, 2008.

[59] H. Misra, D. Mehta, B. K. Mehta, M. Soni, and D. C. Jain, "Study of extraction and HPTLC - UV method for estimation of caffeine in marketed tea (Camellia sinensis) granules," International Journal of Green Pharmacy, vol. 3, no. 1, pp. 47-51, 2009.

[60] T. Kowalska, K. Kaczmarski, and W. Prus, "Handbook of thinlayer chromatography," in Theory and Mechanism of Thin-Layer Chromatography, J. Sherma and B. Fried, Eds., chapter 2, pp. 4780, Marcel Dekker, New York, NY, USA, 3rd edition, 2003.

[61] T. Halkina and J. Sherma, "Comparative evaluation of the performance of silica gel TLC plates and irregular and sphericalparticle HPTLC plates," Acta Chromatographica, no. 17, pp. 261271, 2006.

[62] Martindale, The Extra Pharmacopoeia, The Pharmaceutical Press, London, UK, 30th edition, 1993.

[63] E. Turk, "Phosgene from chloroform," Chemical \& Engineering News, vol. 76, no. 9, p. 6, 1998.

[64] K. E. Maudens, S. M. R. Wille, and W. E. Lambert, "Traces of phosgene in chloroform: consequences for extraction of anthracyclines," Journal of Chromatography B, vol. 848, no. 2, pp. 384390, 2007.

[65] X. Jiang, H. Zhang, M. Wang, and L. Zhang, "Comparison analysis of different parts and geographical origins from southwestern China on artemisinin content of Artemisia annua L," Current Trends in Technology and Science, vol. 2, no. 4, pp. 293-297, 2013.

[66] N. Delabays, X. Simonnet, and M. Gaudin, "The genetics of artemisinin content in Artemisia annua L. and the breeding of high yielding cultivars," Current Medicinal Chemistry, vol. 8, no. 15, pp. 1795-1801, 2001. 

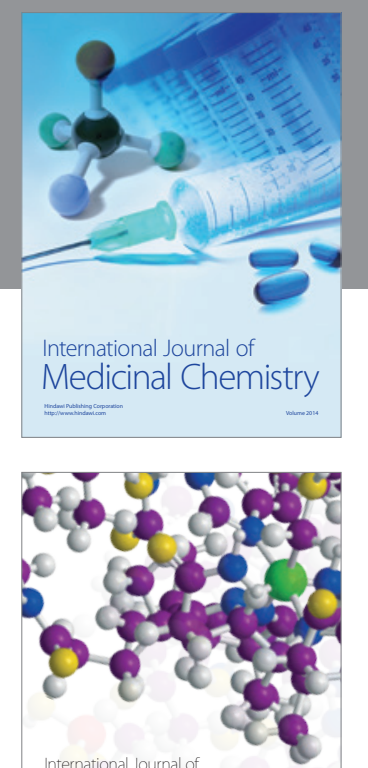

\section{Carbohydrate} Chemistry

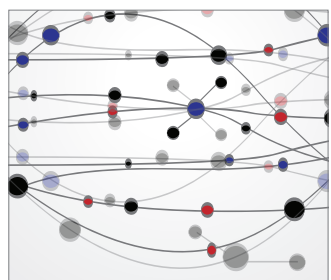

The Scientific World Journal
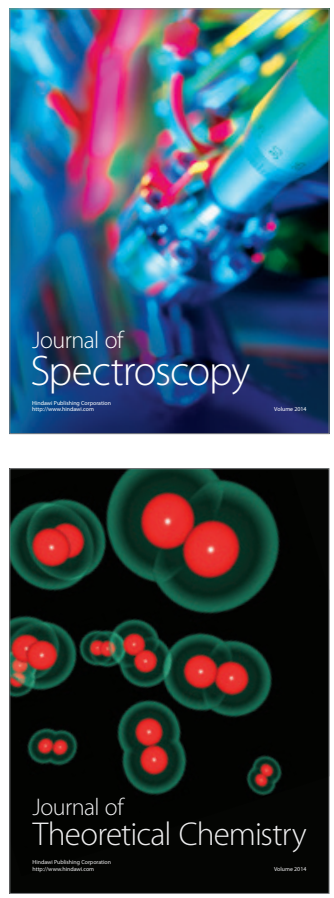
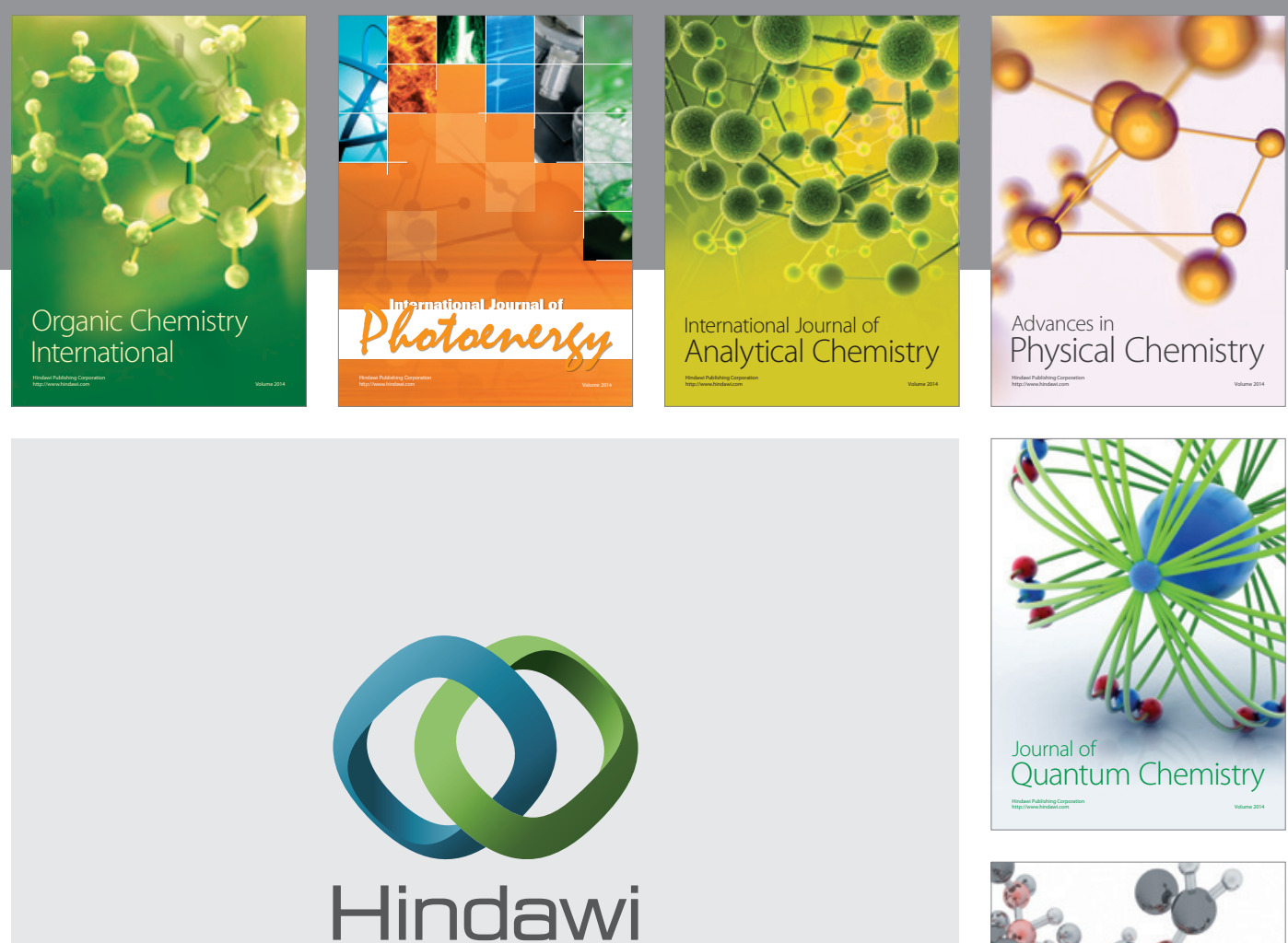

Submit your manuscripts at

http://www.hindawi.com

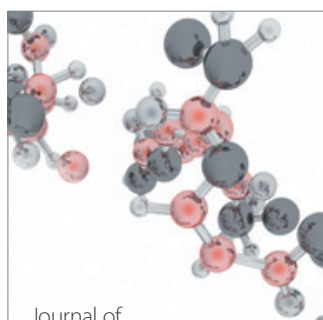

Analytical Methods

in Chemistry

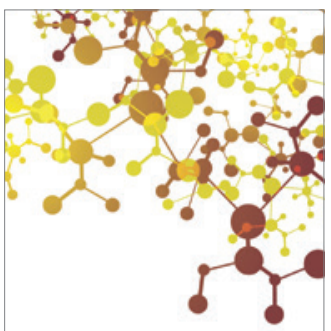

Journal of

Applied Chemistry

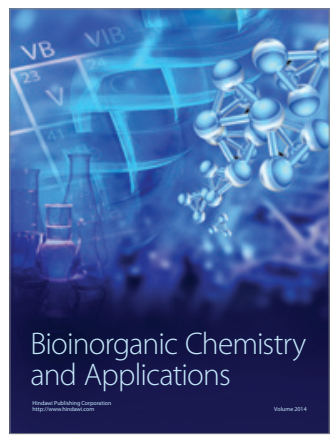

Inorganic Chemistry
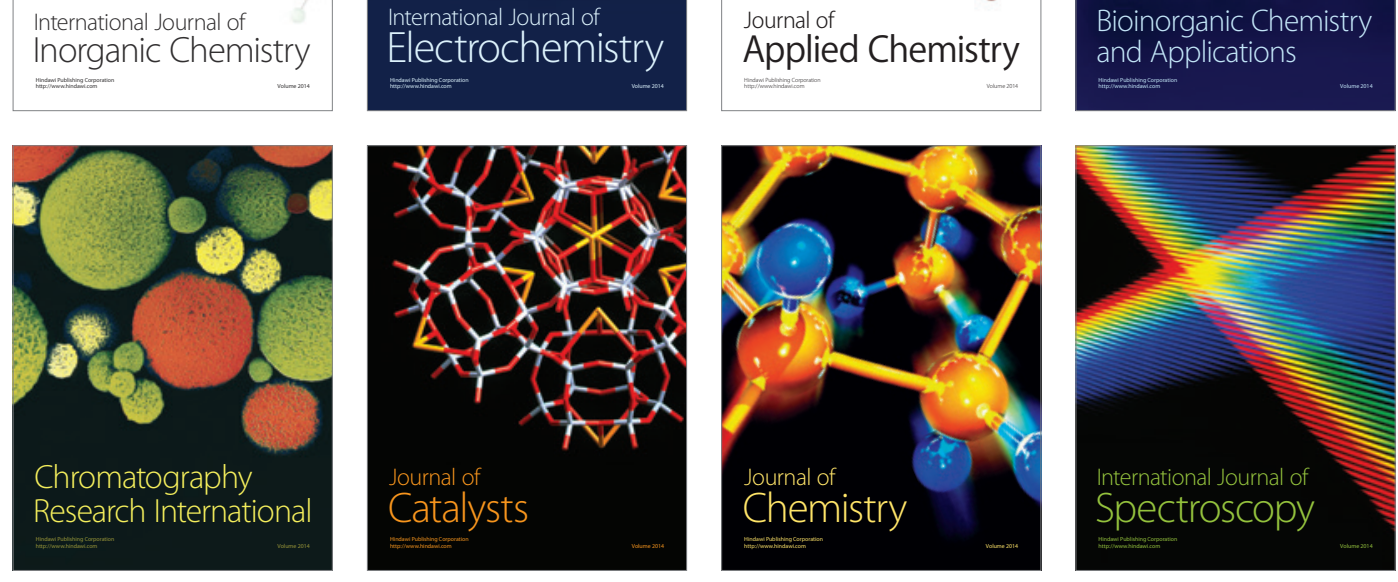